\title{
Lateral Stress Concentration in Localized Interlayer Rock Stratum and the Impact on Deep Multi-Seam Coal Mining
}

\author{
Mingwei Zhang ${ }^{*}$, Hideki Shimada, Takashi Sasaoka, Kikuo Matsui \\ Department of Earth Resources Engineering, Faulty of Engineering, Kyushu University, Fukuoka, Japan \\ Email: "minuei.chiyou@gmail.com
}

Received August 21, 2013; revised September 22, 2013; accepted October 24, 2013

Copyright (C) 2013 Mingwei Zhang et al. This is an open access article distributed under the Creative Commons Attribution License, which permits unrestricted use, distribution, and reproduction in any medium, provided the original work is properly cited.

\begin{abstract}
To explore the impact of lateral stress concentration in interlayer rock stratum on the exploitation of protected coal seam, a field experiment was carried out in a multi-seam mining structure. Lateral stress redistribution and interlayer rock failure behavior were surveyed. Then an assistant numerical investigation was implemented to evolve the effect of liberated seam mining and its influence on stress reconstruction in surrounding rock mass. The cause of lateral stress concentration and its impact were discussed finally. Key findings turn out that a certain lateral stress increases in interlayer rock stratum and concentrates on its lower region. Lateral stress concentration and interlayer rock failure are interactional. The former is an inducing factor of the latter; the latter promotes the increase of concentration degree. Extent of lateral stress concentration increases to the maximum as seam distance is about $50 \mathrm{~m}$. But the efficacy of liberated seam mining decreases as the seam spacing gets larger. Protected seam mining is then classified based upon the impact of lateral stress concentration, which helps to prevent the rock burst hazard and then to achieve a reliable mining in deep mines.
\end{abstract}

Keywords: Lateral Stress Concentration; Interlayer Rock Stratum; Multi-Seam Coal Mining; Stress Relaxation Zone; Floor Failure Behavior

\section{Introduction}

Many geological hazards distinguished from the conventional ones occur gradually in the underground coal mines with the increase of mining depth [1-3], for instance, the high temperature, high ground pressure, seismic hazard, and rock burst. Among them, rock burst hazard greatly hampers the aim of safe production [4,5]. How to effectively prevent and control rock burst is becoming a challenging subject for the mining researchers worldwide [6,7]. In recent years, multi-seam coal mining is treated as an effectively precautionary approach for the deep geologic hazard prevention, especially, for the rock burst $[5,8,9]$. It changes the initial distribution of in-situ stress, improves the plastic deformation of coal and rock mass, weakens the stress concentration in mining region and finally makes the subsequent seams easier to be extracted [10]. One of the multiple coal seams is suggested to be extracted firstly so long as it is relatively nonhazardous or low-hazardous. For the rock burst mines, the firstly extracted coal seam is usually called liberated

${ }^{*}$ Corresponding author. seam. The others are called protected seam. As its advantages, application of multi-seam coal mining enlarges gradually in deep coal mines if only the geological conditions are allowable. It is given the higher priority to control rock burst hazard in application [11].

The reason the multi-seam mining method plays an important role in rock burst prevention is that it generates a stress relaxation zone in surrounding rock mass and the protected seam exploitation in stress relaxation zone can be extracted safely. However, in actual production, it is found that the protected seam exploitation in stress relaxation zone is not always as easy and smooth as it is expected. Especially, in deep coal mining, some unnatural accidents occur occasionally during the exploitation in protected seam. These accidents delay mining schedule and injure the workers in the worse cases. Hence, it should be paid attention during mining. We deduced that the fact protected seam extraction in stress relaxation zone gets unsafe is closely related with a certain degree of lateral stress concentration in the interlayer rock stratum between liberated seam and protected seam. Stress relaxation zone in the multi-seam mining structure is 
determined by the vertical component of principle stress. But the changes of lateral stress in the multi-seam mining structure, especially, in its stress relaxation zone are indeterminate, and also are paid less attention in current researches. Thus, in this study, aiming at the lateral stress changes in interlayer rock stratum, the authors carried out a field investigation in a deep underground coal mine, explored the lateral stress redistribution and interlayer rock failure behavior, discussed the mechanism and impact of lateral stress concentration, which provides the necessary theoretical and practical experience for deep multi-seam coal mining in rock burst prevention.

\section{Three "Zones" of the Multi-Seam Coal Mining Structure}

When multi-seam mining method is used in the prevention of rock burst hazard, the mining region influenced is always divided artificially into several disparate zones based upon the reconstructed stress in the surrounding rock mass of liberated seam extracted [9]. One commonly recognized division is consisted of stress relaxation zone, stress enhancement zone and stress stabilization zone, or other similar definition [12]. The partition is as shown in Figure 1.

Vertical stress in the region that is under and above the extracted coal seam is decreased greatly as the stress transfer [13]. Because of so, this region is called the main stress relaxation zone. Protected seam that locates in this zone is thought to be safely extracted. It is incontrovertible that liberated seam exploitation dramatically lowers the stress concentration degree, weakens the elastic strain energy, and creates positive conditions for the subsequent protected seam mining. Accordingly, rock burst hazard is relieved. With the steeply exploitation in liberated coal seam, dynamic development process of stress redistribution and coal deformation in protected seam wins much attention in current researches, which mainly concentrates on the stress evolution surrounding working

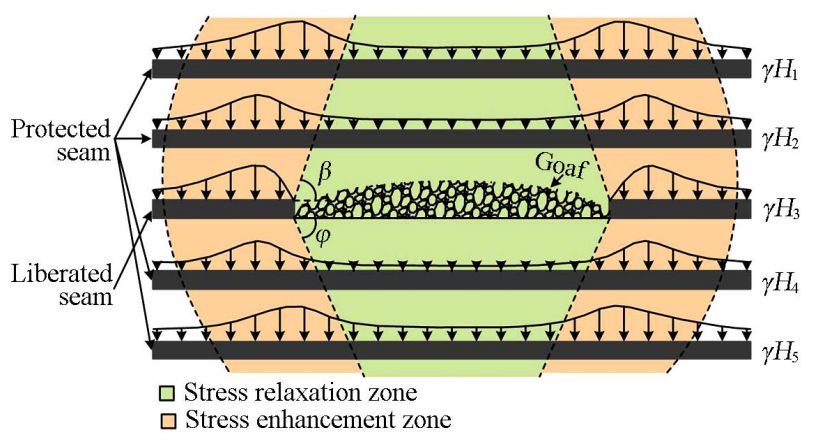

Figure 1. Stress division of the mining region after the liberated seam exploitation. Coal seam in the middle is the liberated seam. Coal seams under and above liberated seam are the protected seams. $\beta$ and $\varphi$ are the upper and lower pressure releasing angle, respectively. face, determination of pressure releasing angle and safe mining area, and optimized layout of roadways [14-16].

\section{Field Experiment of Lateral Stress Redistribution in Interlayer Rock Stratum}

\subsection{Investigation Site and Scheme}

In order to investigate the lateral stress change and redistribution in interlayer rock stratum, a multi-seam coal mining structure in the JNT coal mine, China, was selected as the experiment site. Two coal seams, liberated upper seam (US) and protected lower seam (LS), are worthy of exploitation in this field. Mining depth of upper seam is about $-620 \mathrm{~m}$ in average. Occurrence thickness of both seams is $2.85 \mathrm{~m}$ and $5.0 \mathrm{~m}$. The vertical interlayer spacing is about $42.7 \mathrm{~m}$. Lithology of the interlayer rock mass is the grizzly compact sandstone with a little fracture developed. Its coefficient of hardness is 6 8. Face US-04, neighboring the face US-02 to the east and the face US-06 to the west, is located in the central field. It is the first working face extracted. Its mining length and width are $2770 \mathrm{~m}$ and $180 \mathrm{~m}$, respectively.

Some connection roadways were tunneled for ventilation requirements during the roadway excavation in protected seam. A stress monitoring hole was drilled in one connection roadway that was ahead of the US-04 working face in horizontal distance. Five stress detectors were installed in the central position then. Lateral stress was monitored during the mining process of Face US-04 until the investigation site was $250 \mathrm{~m}$ behind. Meanwhile, four fracture observing holes were drilled with $20 \mathrm{~m}$ interval spacing to cooperate with the stress monitoring. Initial fractures of their inner wall were recorded by borehole imaging instrument, and fracture developing situation was observed until the investigation was terminated. Investigation scheme for this field experiment was shown in Figure 2.

\subsection{Results of Lateral Stress Changes and Interlayer Rock Failure}

Observation results of lateral stress redistribution and interlayer rock failure behavior in these boreholes are shown in Figures 3 and 4.

It indicates that lateral stress redistribution in the stress relaxation zone of interlayer rock mass is greatly influenced by the mining activities in liberated seam. When stress detectors are close to but still ahead of the working face $(-25--10 \mathrm{~m})$, lateral stress in upper rock stratum increases obviously to $32 \mathrm{Mpa}$ but the stress in the lower stratum decreases slightly to $19 \mathrm{Mpa}$. Lateral stress gets less as rock stratum is further away from working face. When the stress detectors are behind of but still close to the working face $(0-20 \mathrm{~m})$, lateral stress redistribution reverses dramatically in a short period. Stress in the 


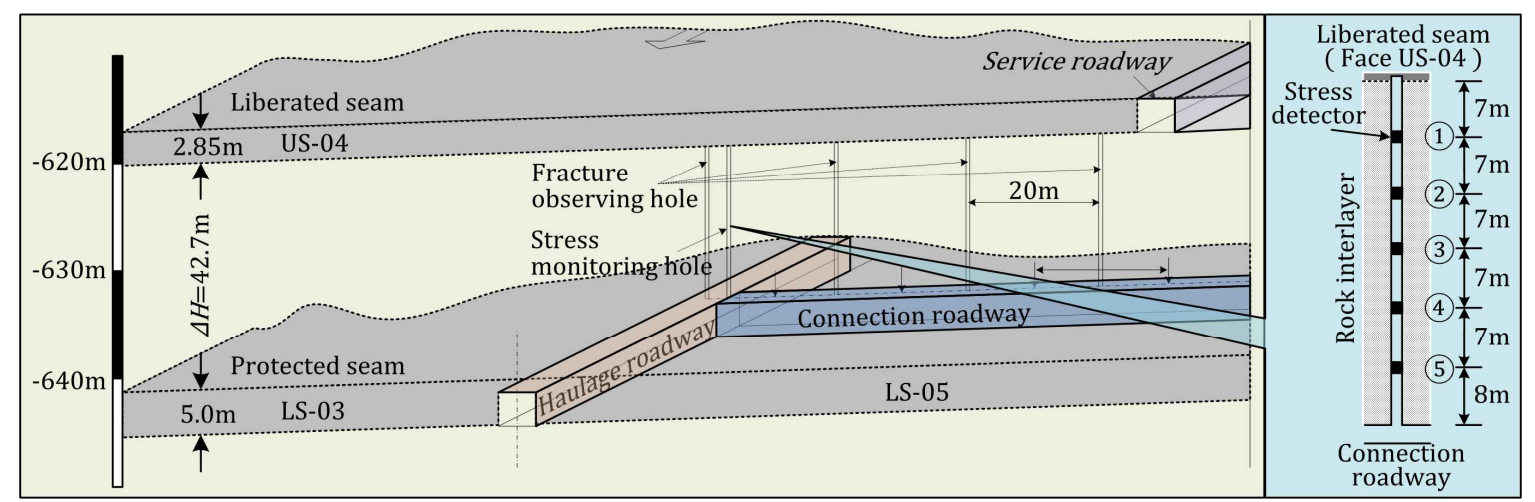

Figure 2. Lateral stress investigation in a multi-seam coal mining structure.

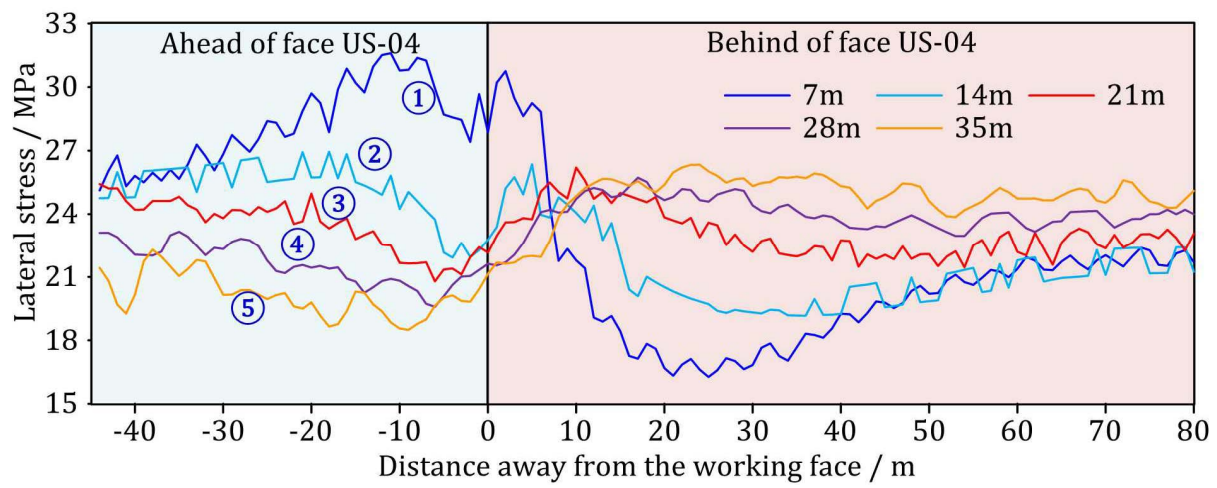

Figure 3. Lateral stress changes in different interlayer rock stratum with the liberated seam exploitation.

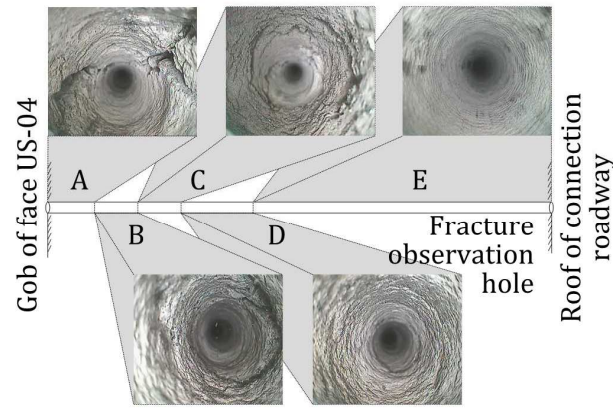

(a)

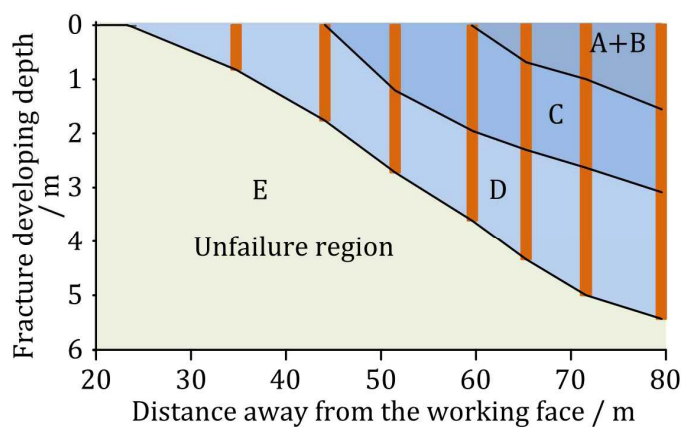

(b)

Figure 4. Plastic failure of interlayer rock mass after the liberated seam exploitation.

upper stratum decreases sharply to $16 \mathrm{Mpa}$, while stress in the lower stratum rises gradually to $26 \mathrm{Mpa}$. It implies that the lateral stress is concentrating in the low region. While as the stress detectors are behind of and away from the working face $(45-80 \mathrm{~m})$, lateral stress becomes stable gradually at a high level of $26 \mathrm{Mpa}$ in average. Field investigation results indicate that lateral stress increases in the stress relaxation zone after liberated seam mining, and gradually results in stress concentration in the lower region of interlayer rock stratum. The lower the rock stratum, the greater the degree of stress concentration gets.

Beside, plastic failure of interlayer rock mass also presents the distinct manifestation. As the stress reconstruction after upper seam mining, inner wall of boreholes suffers serious destruction. In vertical direction, destruction situation of these four boreholes is similar. Fractures are completely developed in their upper part. The closer to the goaf bottom, the more fractures the boreholes have. In the horizontal direction, the destructtion of borehole nearby the centerline is more serious than others, whereas the destruction in the borehole nearby the haulage roadway is the slightest. And in the mining direction, fracture developing depth increases as the investigation site gets far away from the working face. 


\section{Numerical Investigation on the Cause of Lateral Stress Concentration}

\subsection{Construction of Analysis Model}

To explore the cause that results in the lateral stress concentration in stress relaxation zone of interlayer rock stratum, numerical analysis method is introduced into this section. Multi-seam coal mining model shown in Figure 5 is built by the finite element analysis software FLAC $^{3 \mathrm{D}}$ [17]. As it can track the stress changes and failure behavior of analysis object based on the finite difference algorithm and large deformation, this software is particularly appropriate for the researches on rock mass, and has become one of the most important tools in mining engineering. The mechanical properties of coal and rock specimen applied are listed in Table $\mathbf{1 .}$

\subsection{Stress Redistribution in Interlayer Rock Stratum}

Simulated results are shown in Figure 6. It indicates that, as the mining disturbance, in-situ stress reconstructs in a wide region and finally reaches to a new balanced state [18]. In the stress relaxation zone of interlayer rock stra-

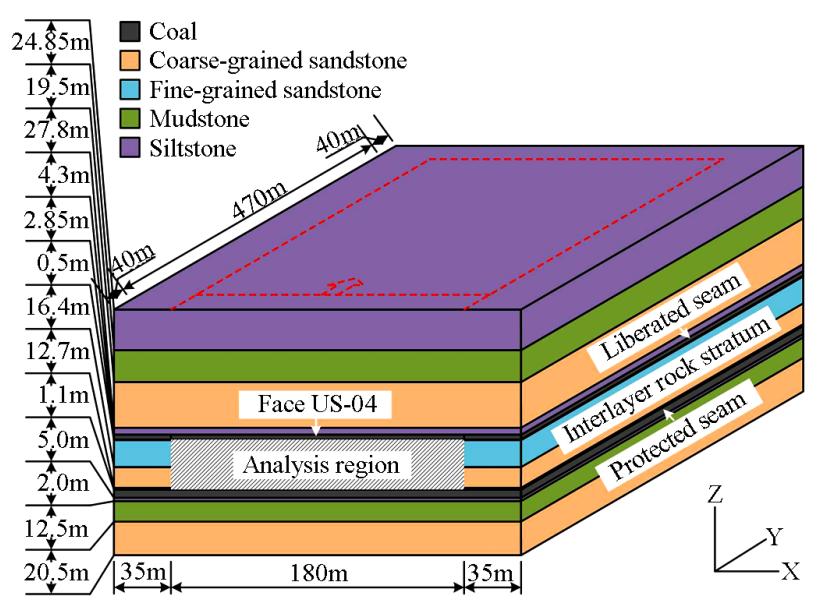

Figure 5. Numerical analysis model of the multi-seam coal mining structure.

Table 1. Basic mechanical properties of coal and rock specimen used in the simulation.

\begin{tabular}{cccccc}
\hline & $\begin{array}{c}\text { Density } \\
\mathrm{kg} \cdot \mathrm{m}^{-3}\end{array}$ & $\begin{array}{c}\text { Elastic } \\
\text { modulus } \\
\mathrm{GPa}\end{array}$ & $\begin{array}{c}\text { Poisson } \\
\text { ratio }\end{array}$ & $\begin{array}{c}\text { Shear } \\
\text { modulus } \\
\mathrm{GPa}\end{array}$ & $\begin{array}{c}\text { Cohesion } \\
\mathrm{Mpa}\end{array}$ \\
\hline Coal & 13.8 & 6.1 & 0.30 & 2.3 & 1.0 \\
Mudstone & 21.4 & 11.5 & 0.25 & 4.8 & 4.2 \\
$\begin{array}{c}\text { Coarse-grained } \\
\text { sandstone }\end{array}$ & 23.5 & 19.8 & 0.23 & 8.5 & 5.2 \\
$\begin{array}{c}\text { Fine-grained } \\
\text { sandstone }\end{array}$ & 24.8 & 20.2 & 0.23 & 9.4 & 5.1 \\
Siltstone & 25.7 & 22.4 & 0.22 & 10.2 & 5.0 \\
\hline
\end{tabular}

tum, vertical stress changes sharply with a great decrement. The ground pressure is released dramatically. However, lateral stress changes following the specific rules. It decreases and is less than the initial value in upper part of interlayer rock, whereas it is obviously greater than the initial value in the lower half region. This case implies that lateral stress increases with the occurrence depth. It leads to a certain extent of stress concentration in the lower rock stratum.

\subsection{Failure State of Interlayer Rock Mass}

Simultaneously, the failure state of interlayer rock mass is shown in Figure 7. As the impact of upper seam mining, plastic failure of interlayer rock mass mainly occurs in two regions: the upper one close to the goaf of liberated seam and the lower one in the immediate roof of protected seam. The former is more serious than the latter. Failure behavior breaks the integrity of interlayer rock mass and changes with the redistributed stress $[19,20]$. It indicates that numerical results are well coincident with the field experiment results.

\subsection{Interaction of Lateral Stress Changes and Interlayer Rock Failure}

Above discussion indicates that lateral stress concentration and interlayer rock failure are interactional. Failure extent of interlayer rock mass depends on the reconstructed lateral stress. Rock failure phenomenon in the bottom of rock stratum does not mean that the lateral stress transfers to other regions. On the contrary, it happens just as the greater action of lateral stress. Under their interaction, lateral stress itself gradually enhances with the increase of occurrence depth, and finally results in the lateral stress concentration in the lower half region (see Figure 8). This interaction continues until an equilibrium state is achieved. In a word, lateral stress reconstruction provides mechanical requirements for the failure of interlayer rock mass, and this plastic rock failure behavior further promotes the lateral stress concentration in stress relaxation zone. Lateral stress concentration increases the elastic strain energy in unbroken interlayer rock mass. Once protected seam is extracted, the interlayer rock mass will cave spontaneously as its roof. In this case, large amount of elastic energy release instantly along with the caving process [21,22]. It undoubtedly induces the hidden accidents and threatens the safe production.

\section{Impact of Lateral Stress Concentration on Protected Seam Exploitation}

As the lateral stress concentrates on the lower part of interlayer rock, the discussion on its scope and extent then becomes necessary. Hence, another seven models 


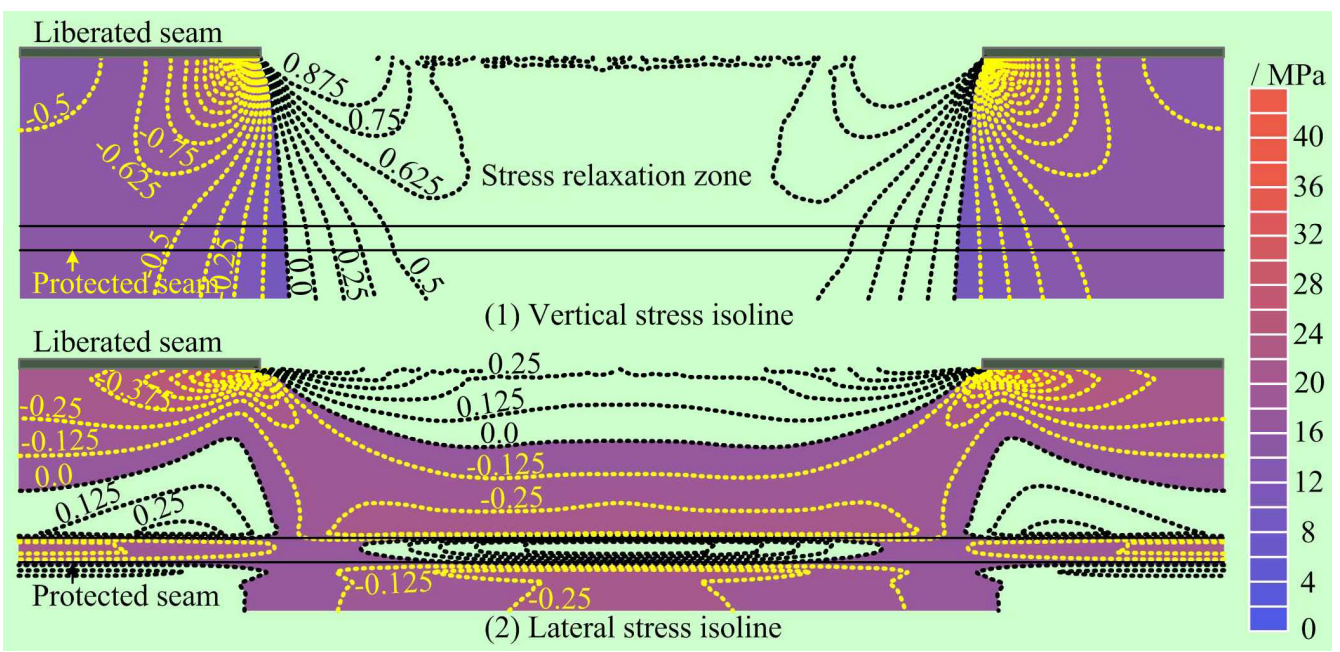

Figure 6. Vertical and lateral stress redistribution in the interlayer rock stratum after liberated seam mining. The value of stress contours is pressure releasing coefficient, which is calculated by the formula: $r=\left(\delta-\delta^{\prime}\right) / \delta$. $\delta$ and $\delta^{\prime}$ are the initial stress and reconstructed stress, respectively. The less the value, the higher the current stress is.

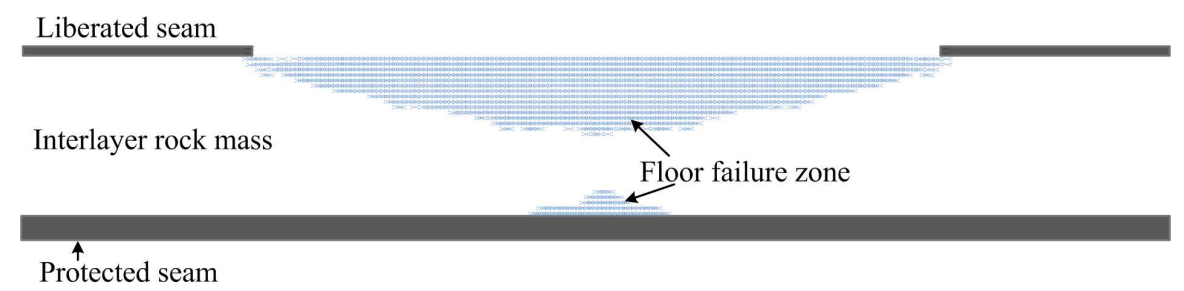

Figure 7. Plastic failure state of interlayer rock mass.

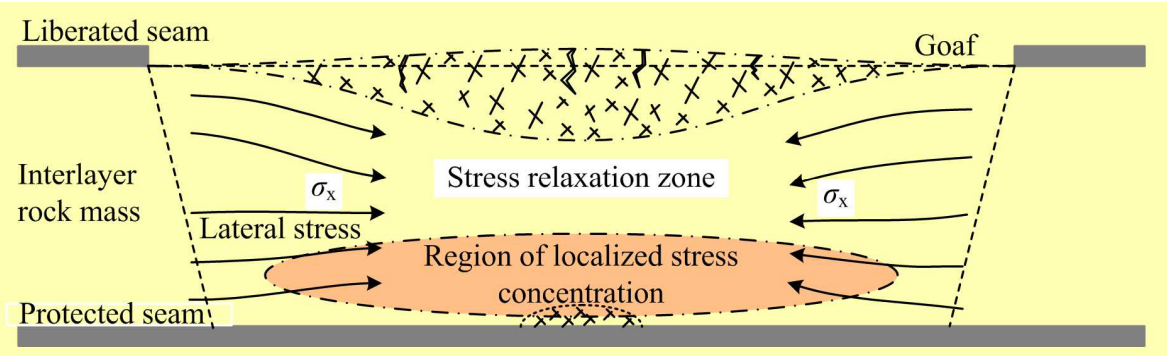

Figure 8. Lateral stress concentration in interlayer rock mass.

with distinct interlayer spacing, $10 \mathrm{~m}$ to $80 \mathrm{~m}$, interval 10 $\mathrm{m}$, were created to explore the impact of lateral stress concentration on protected seam mining, which is assessed by:

$$
\begin{aligned}
& f_{c}=\frac{S_{l}{ }^{\prime}-S_{l}}{S_{l}} \times 100 \% \\
& r_{c}=\frac{C^{\prime}{ }_{\left(f_{c}>0\right)}}{C} \times 100 \%
\end{aligned}
$$

where $S_{l}$ is the initial lateral stress, $S_{l}^{\prime}$ is the reconstructed lateral stress; $C$ is the coverage of stress relaxation zone, and $C^{\prime}$ is the coverage of lateral stress concentration zone; $f_{c}$ and $r_{c}$ are the extent and scope of lateral stress concentration, respectively. Lateral stress redistribution results and its concentration scope and degree in distinct interlayer spacing are shown as Figures 9 and $\mathbf{1 0 .}$

Above figures show that lateral stress is almost completely concentrated on the whole interlayer rock stratum as interlayer spacing is less than $10 \mathrm{~m}$. When the spacing gets large, the location of stress concentration gradually moves downward and its scope increases. The extent of stress concentration rises little by little and reaches to the maximum as interlayer spacing is $50 \mathrm{~m}$, then decreases slowly. The lateral stress concentration behavior is still obvious even as interlayer spacing is greater than $80 \mathrm{~m}$. Based upon the rules of lateral stress concentration, whether protected seam is easy to be extracted can be divided into three types: safe mining in protected seam as interlayer spacing is less than $35 \mathrm{~m}$, risky mining in 


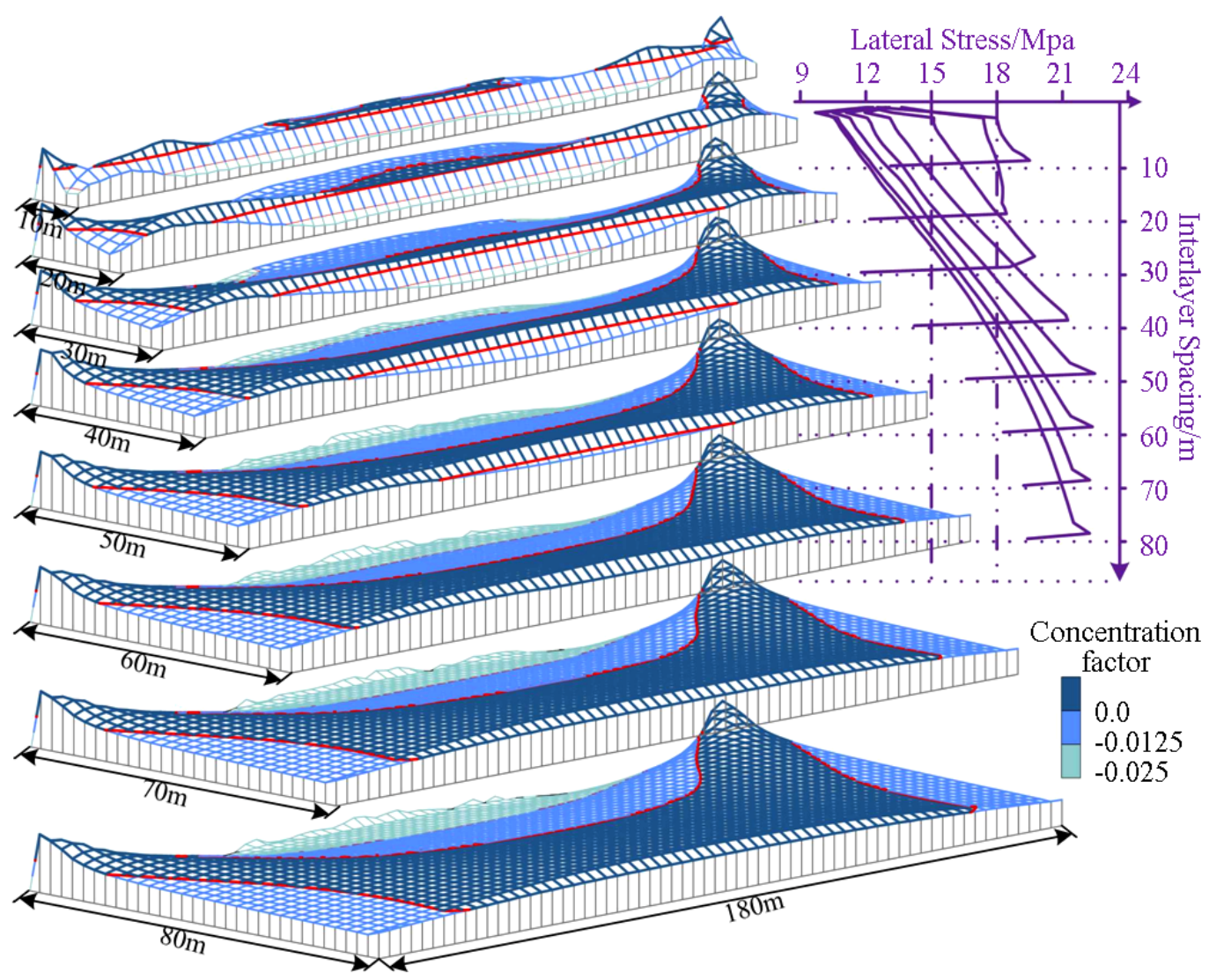

Figure 9. Extent and scope of lateral stress concentration in stress relaxation zone with different spacing.

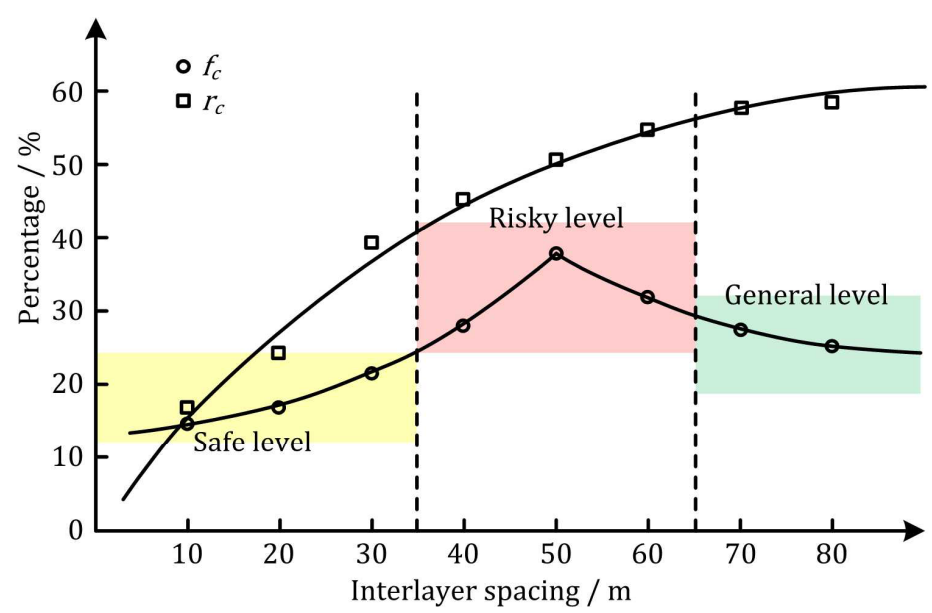

(a)

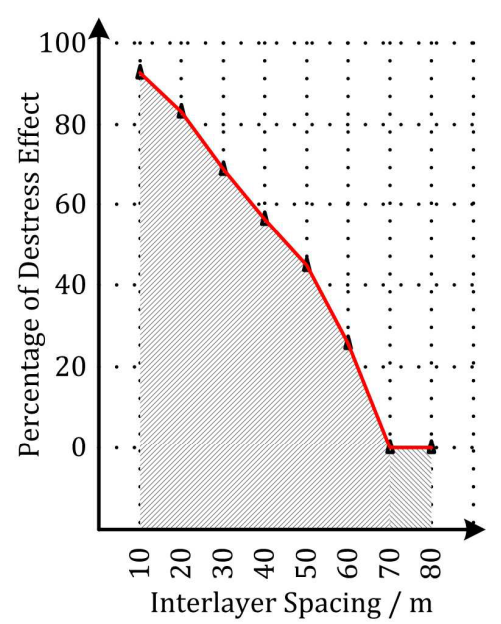

(b)

Figure 10. Assessment of lateral stress concentration in distinct interlayer spacing and the corresponding pressure releasing effect.

protected seam as interlayer spacing is between $35 \mathrm{~m}$ and $65 \mathrm{~m}$, and the general mining in protected seam as interlayer spacing is greater than $65 \mathrm{~m}$.

It indicates that lateral stress concentration in the stress relaxation zone of interlayer rock mass is greatly affected by the interlayer spacing of coal seams. On the one hand, principal stress transfers and reconstructs surrounding the liberated working face; on the other hand, lateral stress itself grows with the increasing interlayer spacing naturally. Besides, the liberated seam mining has limited pressuring releasing efficacy on the exploitation of protected seam, which is closely influenced by the lateral stress concentration in deep multi-seam coal mining. Although protected seam in the stress relaxation zone can 
be relative securely extracted, lateral stress concentration in the interlayer rock mass certainly brings adverse impact to its extraction. The greater the extent and scope of lateral stress concentration is, the higher the potential threaten to protected seam gets.

\section{Conclusions}

Based on the above discussion about the lateral stress concentration in stress relaxation zone of interlayer rock stratum, the following points can be concluded:

1) After liberated seam mining, protected coal seam in its stress relaxation zone is not always safe enough to be extracted as it is generally expected. Decreased vertical stress provides it favorable mechanical environment. However, especially in deep conditions, lateral stress increases instead and can result in a certain extent of stress concentration in the lower half part of interlayer rock stratum. Lateral stress concentration increases elastic strain energy in the unbroken rock mass, and then induces some potential accidents during protected seam mining. This situation is less optimistic for rock burst prevention.

2) The cause that induces the lateral stress concentration in stress relaxation zone is closely related with the interlayer rock failure behavior. Lateral stress concentration and interlayer rock failure are interactional. Lateral stress is also the primary inducing factor of unstable interlayer rock failure. In general, the increased lateral stress provides mechanical requirements for the failure process of interlayer rock mass. Meanwhile, interlayer rock failure further promotes the lateral stress concentration in its stress relaxation zone.

3) Lateral stress concentration occurs in all of the deep multi-seam mining structure. It is affected by the interlayer spacing between coal seams. The stress concentration extent reaches to the maximum as spacing is $50 \mathrm{~m}$. In this case, coal exploitation in protected seam is the most hazardous. The degree of mining safety in protected seam is divided into three types: safe mining as interlayer spacing is less than $35 \mathrm{~m}$, risky mining as interlayer spacing is $35-65 \mathrm{~m}$, and the general mining as interlayer spacing is greater than $65 \mathrm{~m}$. Besides, the pressure releasing effect decreases as the increase of interlayer spacing.

\section{Acknowledgements}

Financial support for this work provided by the Laboratory of Rock Engineering and Mining Machinery, and the G-COE Program in Novel Carbon Resource Sciences, Kyushu University, is gratefully acknowledged.

\section{REFERENCES}

[1] B. B. Tati, "Multi-Seam Coal Mining," Journal of The
South African Institute of Mining and Metallurgy, Vol. 111, No. 4, 2011, pp. 231-242.

[2] S. Khare, Y. V. Rao, C. S. Murthy and H. Vardhan, "Multiple Seam Mining: A Critical Review," Journal of Mines, Metals and Fuels, Vol. 54, No. 12, 2006, pp. 327329.

[3] Z. K. Lin, J. P. Du, J. L. Xu and G. M. Feng, "The Coal Mining Method," China University of Mining and Technology Press, Xuzhou, 2009.

[4] T. V. Lobanova, "Geomechanical State of the Rock Mass at the Tashtagol Mine in the Course of Nucleation and Manifestation of Rock Bursts," Journal of Mining Science, Vol. 44, No. 2, 2008, pp. 146-154. http://dx.doi.org/10.1007/s10913-008-0028-8

[5] L. M. Dou and X. Q. He, "Theory and Technology of Rock Burst Prevention," China University of Mining and Technology Press, Xuzhou, 2001.

[6] L. M. Dou and X. Q. He, "Mining Geophysics," China Science and Culture Press, Beijing, 2002.

[7] R. X. Shen, E. Y. Wang, Z. T. Liu and Z. H. Li, "Rockburst Prevention Mechanism and Technique of Close-Distance Lower Protective Seam Mining," Journal of China Coal Society, Vol. 36, No. S1, 2011, pp. 63-67. (In Chinese)

[8] T. H. Yang, T. Xu, H. Y. Liu, C. A. Tang, B. M. Shi and Q. X. Yu, "Stress-Damage-Flow Coupling Model and Its Application to Pressure Relief Coal Bed Methane in Deep Coal Seam," International Journal of Coal Geology, Vol. 86, No. 4, 2011, pp. 357-366. http://dx.doi.org/10.1016/j.coal.2011.04.002

[9] X. Q. Wu, L. M. Dou, C. G. Lv, A. Y. Cao and M. W. Zhang, "Research on Pressure-Relief Effort of Mining Upper-Protective Seam on Protected Seam," Procedia Engineering, Vol. 26, 2011, pp. 1089-1096. http://dx.doi.org/10.1016/j.proeng.2011.11.2278

[10] D. A. Beck and B. H. Brady, "Evaluation and Application of Controlling Parameters for Seismic Events in HardRock Mines," International Journal of Rock Mechanics and Mining Sciences, Vol. 39, No. 5, 2002, pp. 633-642. http://dx.doi.org/10.1016/S1365-1609(02)00061-8

[11] Ministry of Coal Industry, "National Provisional Rules of Safe Mining in Rock Burst Seam," 1987.

[12] W. Yang, B. Q. Lin, Y. A. Qu, Z. W. Li, C. Zhai, L. L. Jia and W. Q. Zhao, "Stress Evolution with Time and Space during Mining of a Coal Seam," International Journal of Rock Mechanics and Mining Sciences, Vol. 48, No. 7, 2011, pp. 1145-1152. http://dx.doi.org/10.1016/j.ijrmms.2011.07.006

[13] B. H. G. Brady and E. T. Brown, "Rock Mechanics for Underground Mining," Kluwer Academic Publishers, 2004.

[14] W. Yang, B. Q. Lin, Y. A. Qu, S. Zhao, C. Zhai, L. L. Jia and W. Q. Zhao, "Mechanism of Strata Deformation under Protective Seam and Its Application for Relieved Methane Control," International Journal of Coal Geology, Vol. 85, No. 3-4, 2010, pp. 300-306. http://dx.doi.org/10.1016/i.coal.2010.12.008

[15] J. C. Wang and H. B. Zhao, "Numerical Simulation on 
Deformation Rule of Protected Coal Seam under Upper Protective Seam Method," Disaster Advances, Vol. 3, No. 4, 2010, pp. 383-387.

[16] Y. K. Liu, F. B. Zhou, L. Liu, C. Liu and S. Y. Hu, “An Experimental and Numerical Investigation on the Deformation of Overlying Coal Seams above Double-Seam Extraction for Controlling Coal Mine Methane Emissions," International Journal of Coal Geology, Vol. 87, No. 2, 2011, pp. 139-149. http://dx.doi.org/10.1016/j.coal.2011.06.003

[17] N. Z. Xu and L. Han, "Pressure-relief Effect of Coal Rock Body of Long Distance Lower Protective Seam Mined Based on FLAC3D," Journal of Coal Science and Engineering, Vol. 16, No. 4, 2010, pp. 341-346. http://dx.doi.org/10.1007/s12404-010-0402-2

[18] H. Guo, L. Yuan, B. T. Shen, Q. D. Qu and J. H. Xue, "Mining-Induced Strata Stress Changes, Fractures and Gas Flow Dynamics in Multi-Seam Longwall Mining," International Journal of Rock Mechanics and Mining Sciences, Vol. 54, 2012, pp. 129-139. http://dx.doi.org/10.1016/j.ijrmms.2012.05.023

[19] A. A. Nasedkina, A. V. Nasedkin and G. Iovane, "A Model for Hydrodynamic Influence on a Multi-Layer
Deformable Coal Seam," Computational Mechanics, Vol. 41, No. 3, 2008, pp. 379-389.

http://dx.doi.org/10.1007/s00466-007-0194-6

[20] S. Prusek and S. Bock, "Assessment of Rock Mass Stresses and Deformations around Mine Workings Based on Three-Dimensional Numerical Modeling," Archives of Mining Sciences, Vol. 53, No. 3, 2008, pp. 349-360.

[21] Z. Q. Yin, X. B. Li, J. F. Jin, X. Q. He and K. Du, "Failure Characteristics of High Stress Rock Induced by Impact Disturbance under Confining Pressure Unloading," Transactions of Nonferrous Metals Society of China, Vol. 22, No. 1, 2012, pp. 175-184. http://dx.doi.org/10.1016/S1003-6326(11)61158-8

[22] R. Weinberger, Y. Eyal and N. Mortimer, "Formation of Systematic Joints in Metamorphic Rocks Due to Release of Residual Elastic Strain Energy, Otago Schist, New Zealand," Journal of Structural Geology, Vol. 32, No. 3, 2010, pp. 288-305.

http://dx.doi.org/10.1016/j.jsg.2009.12.003 